Article

\title{
High Frequency Needle Ultrasonic Transducers Based on Lead-Free Co Doped $\mathrm{Na}_{0.5} \mathrm{Bi}_{4.5} \mathrm{Ti}_{4} \mathrm{O}_{15}$ Piezo-Ceramics
}

\author{
Chunlong Fei ${ }^{1,+}$, Tianlong Zhao ${ }^{1,+}$, Danfeng Wang ${ }^{1,2}$, Yi Quan ${ }^{3}$, Pengfei Lin ${ }^{1}$, Di Li $^{1}$, \\ Yintang Yang ${ }^{1}$, Jianzheng Cheng ${ }^{2}$, Chunlei Wang ${ }^{4}$, Chunming Wang ${ }^{4, *}$ and Qifa Zhou ${ }^{5, *}$ \\ 1 School of Microelectronics, Xidian University, Xi'an 740071, China; clfei@xidian.edu.cn (C.F.); \\ zhaot1@xidian.edu.cn (T.Z.); jikedandan@163.com (D.W.); pflinxidian@163.com (P.L.); \\ lidi2004@126.com (D.L.); yangyt@xidian.edu.cn (Y.Y.) \\ 2 School of Electronic and Electrical Engineering, Wuhan Textile University, Wuhan 430200, China; \\ jzcheng@wtu.edu.cn \\ 3 Electronic Materials Research Laboratory, Key Laboratory of the Ministry of Education \& International \\ Center for Dielectric Research, Xi'an Jiaotong University, Xi'an 740049, China; quanyi@stu.xjtu.edu.cn \\ 4 School of Physics, State Key Laboratory of Crystal Materials, Shandong University, Jinan 250100, China; \\ wangcl@sdu.edu.cn \\ 5 Department of Ophthalmology and Biomedical Engineeing, University of Southern California, \\ Los Angeles, CA 90089-1111, USA \\ * Correspondence: wangcm@sdu.edu.cn (C.W.); qifazhou@usc.edu (Q.Z.) \\ + The authors contributed equally to this work.
}

Received: 20 April 2018; Accepted: 5 June 2018; Published: 10 June 2018

\begin{abstract}
This paper describes the design, fabrication, and characterization of tightly focused ( $f$-number close to 1) high frequency needle-type transducers based on lead-free $\mathrm{Na}_{0.5} \mathrm{Bi}_{4.5} \mathrm{Ti}_{3.975} \mathrm{Co}_{0.025} \mathrm{O}_{15}$ (NBT-Co) piezo-ceramics. The NBT-Co ceramics, are fabricated through solid-state reactions, have a piezoelectric coefficient $d_{33}$ of $32 \mathrm{pC} / \mathrm{N}$, and an electromechanical coupling factor $k_{t}$ of $35.3 \%$. The high Curie temperature $\left(670{ }^{\circ} \mathrm{C}\right)$ indicates a wide working temperature range. Characterization results show a center frequency of $70.4 \mathrm{MHz}$ and a $-6 \mathrm{~dB}$ bandwidth of $52.7 \%$. Lateral resolution of $29.8 \mu \mathrm{m}$ was achieved by scanning a $10 \mu \mathrm{m}$ tungsten wire target, and axial resolution of $20.8 \mu \mathrm{m}$ was calculated from the full width at half maximum (FWHM) of the pulse length of the echo. This lead-free ultrasonic transducer has potential applications in high resolution biological imaging.
\end{abstract}

Keywords: lead-free piezoelectric materials; high frequency ultrasonic transducer; needle-type; high spatial resolution

\section{Introduction}

Tightly focused high frequency ultrasonic transducers have many clinical applications, ranging from imaging the skin and eye to small animal imaging, because of their improved image resolution [1-4]. The improvement of axial resolution is due to a reduction in wavelength, and thus pulse duration, for a fixed number of cycles per pulse. The improvement of on-focus lateral resolution is due to the small $f$-number, defined as the ratio of the focal distance to the spatial dimension of the transducer, of the tightly focused transducer and the wavelength. As the key component of ultrasonic transducers, piezoelectric materials such as zinc oxide $(\mathrm{ZnO})$ and aluminum nitride $(\mathrm{AlN})$ piezoelectric films [5,6], lead oxide based ferroelectrics, especially the lead zirconate titanate (PZT) system, lead niobiumzine zirconate titanate (PMN-PT) crystal [7-9], lithium niobate $\left(\mathrm{LiNbO}_{3}\right)$ single crystal [4], and lead-free piezoelectric ceramics [10-12] have been investigated extensively. Among them, due 
to their environmental friendliness, simple preparation methods, and relatively low cost, lead-free piezoelectric ceramics have attracted significant interest.

Lead-free $\mathrm{Na}_{0.5} \mathrm{Bi}_{4.5} \mathrm{Ti}_{4} \mathrm{O}_{15}$ (abbreviated as NBT) based materials have been studied recently for their interesting properties, such as high Curie temperature, low dielectric loss, and reasonable piezoelectric behaviors [13-15]. However, the piezoelectric performance of pure NBT ceramics is quite weak; the value of piezoelectric coefficient $d_{33}$ is $16 \mathrm{pC} / \mathrm{N}$ [16]. Researchers have made many attempts, such as A- or B-site modification and grain orientation techniques, to overcome these shortcomings and improve the piezoelectric and ferroelectric properties of NBT ceramics $[13,17,18]$. In these studies, the B-site acceptor modification improved the piezoelectricity of NBT ceramics significantly [15]. For example, the value of $d_{33}$ of Co-doped NBT (NBT-Co) piezoelectric ceramics is over $30 \mathrm{pC} / \mathrm{N}$, which is almost twice of the value of pure NBT ceramics.

To the best of the authors' knowledge, transducers based on NBT-based ceramics for high frequency ultrasound applications have rarely been reported. In this paper, NBT-Co ceramics were prepared and systematically investigated. A tightly focused needle-type ultrasonic transducer with center frequency of $70 \mathrm{MHz}$ was designed and fabricated based on the performance of the NBT-Co ceramics. The electrical and acoustic properties of the transducer were investigated in detail, which demonstrated the great potential of this lead-free transducer for application in high resolution biological and medical imaging.

\section{Fabrication and Characterization of Co-Doped $\mathrm{Na}_{0.5} \mathrm{Bi}_{4.5} \mathrm{Ti}_{4} \mathrm{O}_{15}$ Ceramics}

\subsection{Fabrication}

A conventional mixed-oxide technique was used to prepare sodium-potassium bismuth titanate (NBT-Co) piezoelectric ceramics. Analytical grade $\mathrm{Na}_{2} \mathrm{CO}_{3}(99.9 \%), \mathrm{Bi}_{2} \mathrm{O}_{3}(99.9 \%), \mathrm{TiO}_{2}(99.9 \%)$, and $\mathrm{Co}_{2} \mathrm{O}_{3}(99.9 \%)$ were selected as starting materials. The composition investigated in the present work is $\mathrm{Na}_{0.5} \mathrm{Bi}_{4.5} \mathrm{Ti}_{3.975} \mathrm{Co}_{0.025} \mathrm{O}_{15}$ (abbreviated as NBT-Co). The mixture was wet milled in polyethylene bottles with $\mathrm{ZrO}_{2}$ balls for $12 \mathrm{~h}$ in ethanol and calcined at $800{ }^{\circ} \mathrm{C}$ for $2 \mathrm{~h}$. Then the mixture was milled again in the same conditions. The milled powders were dried, ground, and granulated with polyvinyl alcohol (PVA) binder, then pressed into disks at a pressure of $150 \mathrm{MPa}$. The green compacts were put into a sealed crucible fully surrounded with powder having the same composition and sintered at $1080-1100{ }^{\circ} \mathrm{C}$ for $3 \mathrm{~h}$. After cooling to room temperature freely, the size of the final samples was $13 \mathrm{~mm}$ in diameter and $0.5 \mathrm{~mm}$ in thickness.

Phase structure was determined by X-ray diffraction technology with $\mathrm{CuK \alpha} \alpha_{1}(\lambda=1.540596 \AA)$ radiation (D8 Advance; Bruker AXS GMBH, Karlsruhe, Germany). Surface micromorphology of the sintered ceramics was detected by scanning electron microscopy (SEM, S-4800, Hitachi, Tokyo, Japan). The piezoelectric coefficient $d_{33}$ was measured by a quasi-static $d_{33}$ meter (ZJ-2, Institute of Acoustics, Academia Sinica, Taipei, Taiwan). Dielectric measurements were performed with a 4294A impedance analyzer (Agilent Technologies, Santa Clara, CA, USA). The electromechanical coupling factors $\left(k_{p}, k_{t}\right)$, and frequency constants $\left(N_{p}, N_{t}\right)$ were calculated according to IEEE standards [19].

\subsection{Characterization}

Figure 1 shows the X-ray diffraction pattern of the NBT-Co piezoelectric ceramic powder. The diffraction pattern is in agreement with the diffraction data for NBT ceramics, indicating that the Co doping does not change the crystal structure of NBT ceramics. The surface of the NBT-Co piezoelectric ceramics is shown in the inset scanning electron microscopy (SEM) image. As shown, the sample has a dense structure and plate-like morphology, corresponding with the high anisotropy of NBT-Co ceramics. 


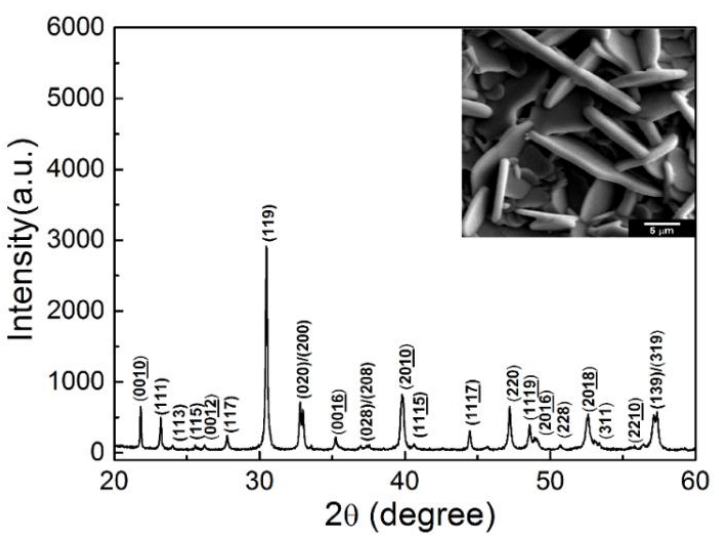

Figure 1. The X-ray diffraction pattern and scanning electron microscopy (SEM) image (embedded) of the Co-doped $\mathrm{Na}_{0.5} \mathrm{Bi}_{4.5} \mathrm{Ti}_{4} \mathrm{O}_{15}$ (NBT-Co) sample.

Detailed room temperature electrical properties of the NBT-Co polycrystalline piezoelectric ceramics are in Table 1 . The piezoelectric coefficient $d_{33}$ of NBT-Co ceramics was found to be $32 \mathrm{pC} / \mathrm{N}$, with a large enhancement of double that of pure NBT ceramics. In addition, the relative permittivity $\varepsilon$ and dielectric loss $\tan \delta$ at $1 \mathrm{MHz}$ are 148 and $0.26 \%$, respectively. Furthermore, the planar electromechanical coupling factor $\left(k_{p}\right)$ and thickness electromechanical coupling factor $\left(k_{t}\right)$ were calculated according to the resonance method and found to be $5.2 \%$ and $35.3 \%$, respectively. In addition, the planar frequency constant $\left(N_{p}\right)$ and thickness frequency constant $\left(N_{t}\right)$ makes little difference and were found to be 2320 and 2280, respectively.

Table 1. Electrical properties of Co-doped $\mathrm{Na}_{0.5} \mathrm{Bi}_{4.5} \mathrm{Ti}_{4} \mathrm{O}_{15}$ (NBT-Co) ceramics.

\begin{tabular}{cccccccc}
\hline $\mathrm{T}_{\mathrm{c}}\left({ }^{\circ} \mathrm{C}\right)$ & $\varepsilon_{33}{ }^{\mathrm{T}}$ & $\operatorname{Tan} \delta(\%)$ & $d_{33}(\mathrm{pC} / \mathrm{N})$ & $k_{p}(\%)$ & $k_{t}(\%)$ & $N_{p}(\mathrm{~Hz} \cdot \mathrm{m})$ & $N_{t}(\mathrm{~Hz} \cdot \mathrm{m})$ \\
\hline 670 & 148 & 0.26 & 32 & 5.2 & 35.3 & 2320 & 2280 \\
\hline
\end{tabular}

Figure 2 shows the relative permittivity $\varepsilon$ and dielectric loss $\tan \delta$ measured at $1 \mathrm{kHz}, 10 \mathrm{kHz}$, $100 \mathrm{kHz}$, and $1 \mathrm{MHz}$ as a function of temperature for the cobalt-modified NBT piezoelectric ceramics. The Curie temperature was found to be $670{ }^{\circ} \mathrm{C}$ and remains unchanged at all measured frequencies, indicating typical diffuse phase transition characteristics. It can be seen that the dielectric loss $\tan \delta$ is lower than $1 \%$ even when the temperature reached $400{ }^{\circ} \mathrm{C}$; this is important for high temperature piezoelectric applications.

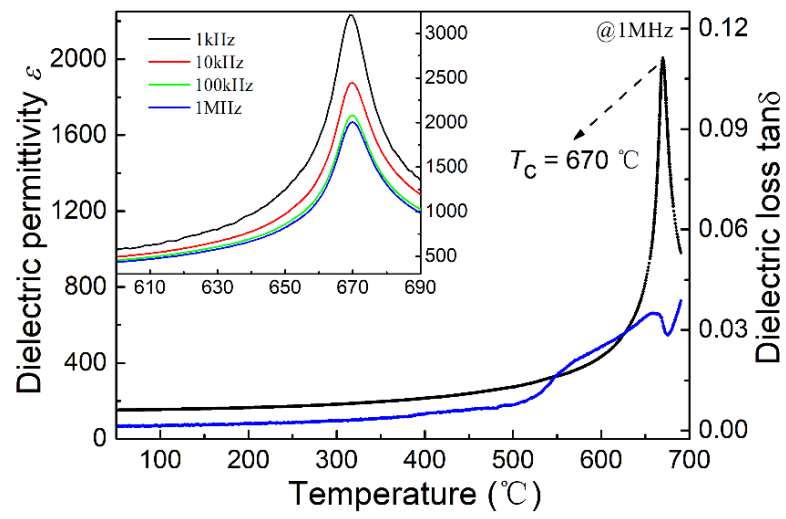

Figure 2. The relative permittivity (black curve) and dielectric loss (blue curve) of the Co-doped $\mathrm{Na}_{0.5} \mathrm{Bi}_{4.5} \mathrm{Ti}_{4} \mathrm{O}_{15}$ (NBT-Co) ceramic measured at $1 \mathrm{MHz}$ and other frequencies (embedded) as a function of temperature. 


\section{Design, Fabrication, and Characterization of Tightly Focused Needle Ultrasonic Transducer}

\subsection{Transducer Design and Fabrication}

Krimholtz, Leadom, and Mettaei (KLM) model-based simulation software PiezoCAD (Sonic Concepts, Woodinville, WA, USA) was used for transducer design. Finite element modeling software Field II was utilized to give the theoretical analysis of imaging performance by simulating the intensity profile in the X-Z plane. Key parameters of NBT-Co ceramics used for simulation are in Table 2. During the simulation, E-solder 3022 and Parylene $C$ were selected as backing and matching materials, respectively, which is consistent with the experiment. The pulse-echo simulation results (shown in Figure 3a) show transducer design with center frequency of $76.2 \mathrm{MHz}$ and $-6 \mathrm{~dB}$ bandwidth of $31.8 \%$; the Field II simulation results (shown in Figure $3 \mathrm{~b}$ ) show the on-focus $-6 \mathrm{~dB}$ beam width to be less than $30 \mu \mathrm{m}$ for NBT-Co transducer with $f$-number $=1$. All these results suggest that NBT-Co ceramics can be used for high frequency and high resolution transducer applications.
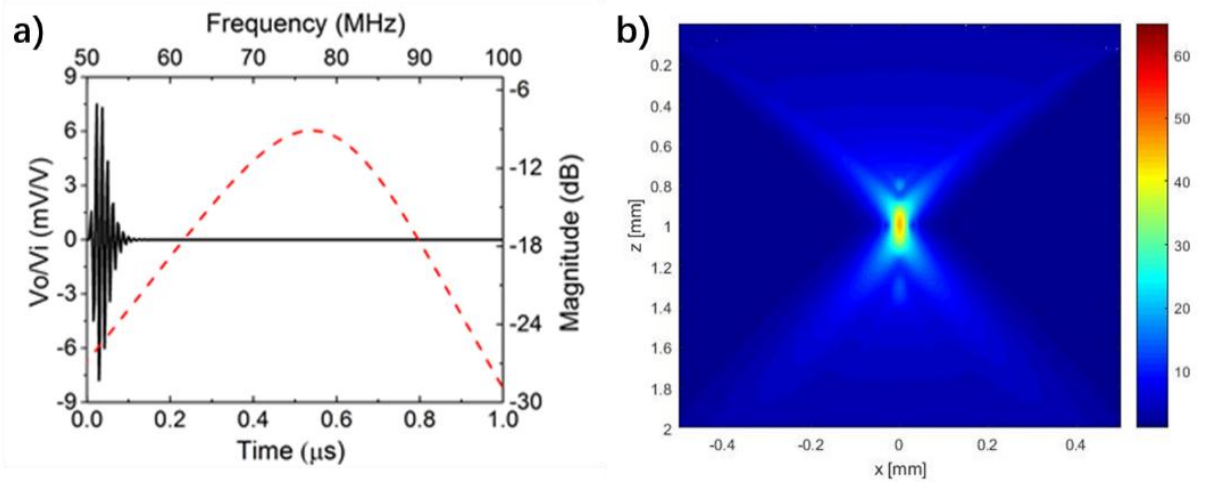

Figure 3. (a) Modelling results of Co-doped $\mathrm{Na}_{0.5} \mathrm{Bi}_{4.5} \mathrm{Ti}_{4} \mathrm{O}_{15}$ (NBT-Co) single element transducer from Krimholtz, Leadom, and Mettaei (KLM) model-based simulation software PiezoCAD. (b) Simulated intensity profile in X-Z plane of NBT-Co transducer with $f$-number of 1 .

Table 2. Parameters of Co-doped $\mathrm{Na}_{0.5} \mathrm{Bi}_{4.5} \mathrm{Ti}_{4} \mathrm{O}_{15}$ (NBT-Co) ceramics used for PiezoCAD modeling.

\begin{tabular}{cc}
\hline Property & NBT-Co \\
\hline Longitudinal velocity $v$ & $4600 \mathrm{~m} / \mathrm{s}$ \\
Density $\rho$ & $6500 \mathrm{~kg} / \mathrm{m}^{3}$ \\
Acoustic impedance $Z$ & $29.9 \mathrm{MRayl}$ \\
Clamped relative dielectric constant $\varepsilon_{r}$ & 20 \\
Dielectric loss tan $\delta$ & 0.0026 \\
Thickness electromechanical coupling $k_{t}$ & 0.353 \\
Piezoelectric coefficient $d_{33}$ & $32 \mathrm{pC} / \mathrm{N}$ \\
\hline
\end{tabular}

Based on the prepared NBT-Co piezoelectric ceramics, a high frequency press-focused needle-type transducer was design and fabricated. The schematic diagram and photograph of the designed NBT-Co high frequency ultrasonic transducer are shown in Figure 4. Firstly, the NBT-Co ceramic was manually lapped to around $30 \mu \mathrm{m}$, per the design. Au $(100 \mathrm{~nm})$ electrodes were sputtered on one side of the NBT-Co ceramic; E-solder 3022 was then cast on this side as the backing material, which was lapped to $2 \mathrm{~mm}$. The sample was diced to $0.7 \times 0.7 \mathrm{~mm}^{2}$ posts using a dicing saw (DAD 323, Disco, Tokyo, Japan) and housed inside a polyimide tube, which provided electrical isolation for the element. The entire assembly was sealed in a steel needle. A lead wire was connected to the backing layer at one side and a SubMiniature version A (SMA) connector at the other side. Then a $100 \mathrm{~nm}$ Au layer was sputtered across the front surface to form the ground plane connection. The transducer was press-focused at $90^{\circ} \mathrm{C}$ by a highly polished chrome/steel ball bearings with diameter of $2 \mathrm{~mm}$ using a set of customer 
designed fixtures. Finally, a PDS 2010 Labcoator (Specialty Coating Systems, Indianapolis, IN, USA) was used to vapor-deposit a $\sim 8 \mu \mathrm{m}$ layer of Parylene $\mathrm{C}$ on the front face of the transducer to serve as an acoustic matching layer.

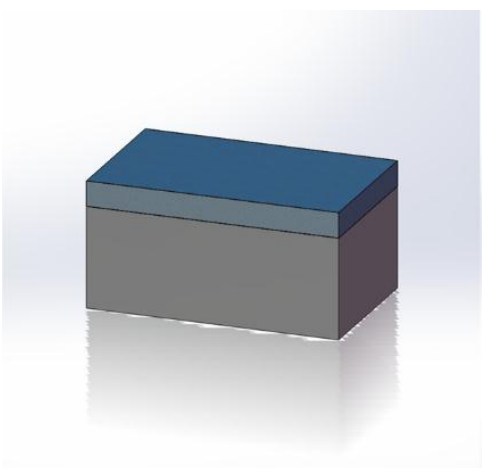

Step1: Lapping NBT-Co ceramic and adding backing layer.

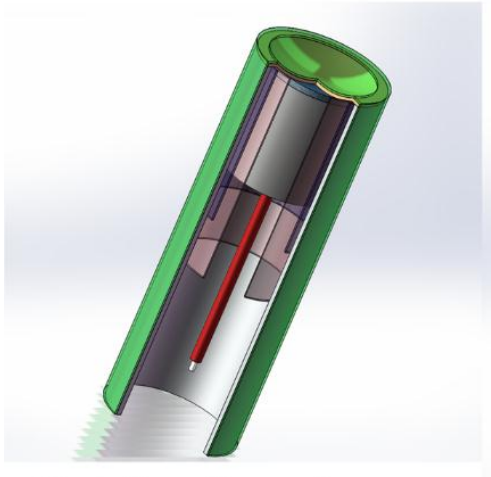

Step4: Depositing parylene as matching and protecting layer.

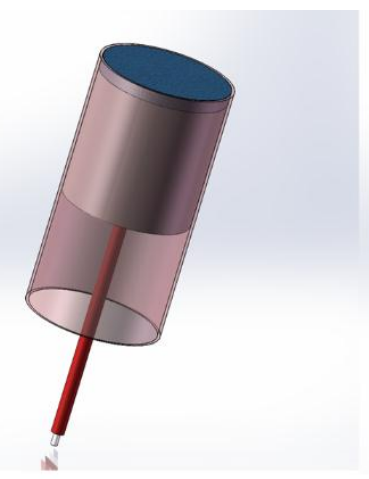

Step2: After dicing, a small post was inserted inside a polyimide tube.

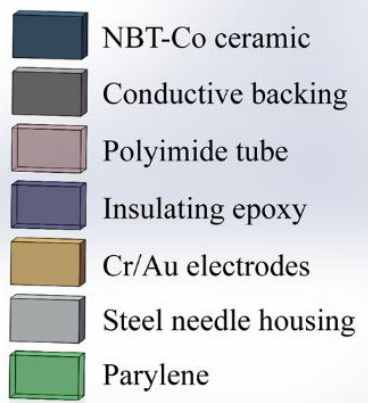

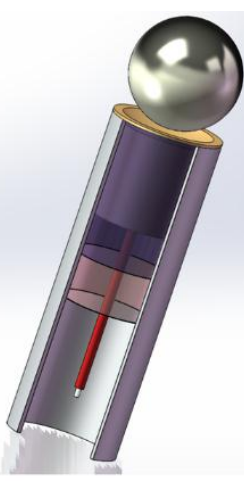

Step3: Housing the sample into a steel needle, sputtering $\mathrm{Cr} / \mathrm{Au}$ electrodes, and then press-focusing.

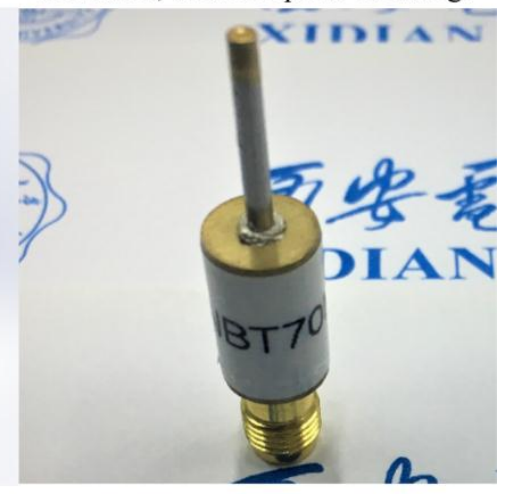

Figure 4. The schematic diagram and photograph of the Co-doped $\mathrm{Na}_{0.5} \mathrm{Bi}_{4.5} \mathrm{Ti}_{4} \mathrm{O}_{15}(\mathrm{NBT}-\mathrm{Co})$ needle transducer.

\subsection{Transducer Characterization}

The pulse-echo response of the NBT-Co needle transducer was measured in distilled water through conventional means [4]. The pulse-echo response and frequency spectrum of the NBT-Co press-focused transducer are shown in Figure 5. The measured transducer performance is in Table 3. As can be seen, the NBT-Co transducer exhibits center frequency of $70.4 \mathrm{MHz}$ and a $-6 \mathrm{~dB}$ bandwidth of $52.7 \%$. The $f$-number was calculated to be 1.03 . The small $f$-number, which leads to narrow beam width, is expected to yield high lateral resolution.

Table 3. Measured Co-doped $\mathrm{Na}_{0.5} \mathrm{Bi}_{4.5} \mathrm{Ti}_{4} \mathrm{O}_{15}$ (NBT-Co) transducer performance.

\begin{tabular}{cc}
\hline Property & NBT-Co Transducer \\
\hline Center frequency (MHz) & 70.4 \\
Peak to peak Voltage (mV) @ 0 dB gain & 123 \\
-6dB Bandwidth & $52.7 \%$ \\
Focus depth (mm) & 1.02 \\
$f$-number & 1.03 \\
\hline
\end{tabular}




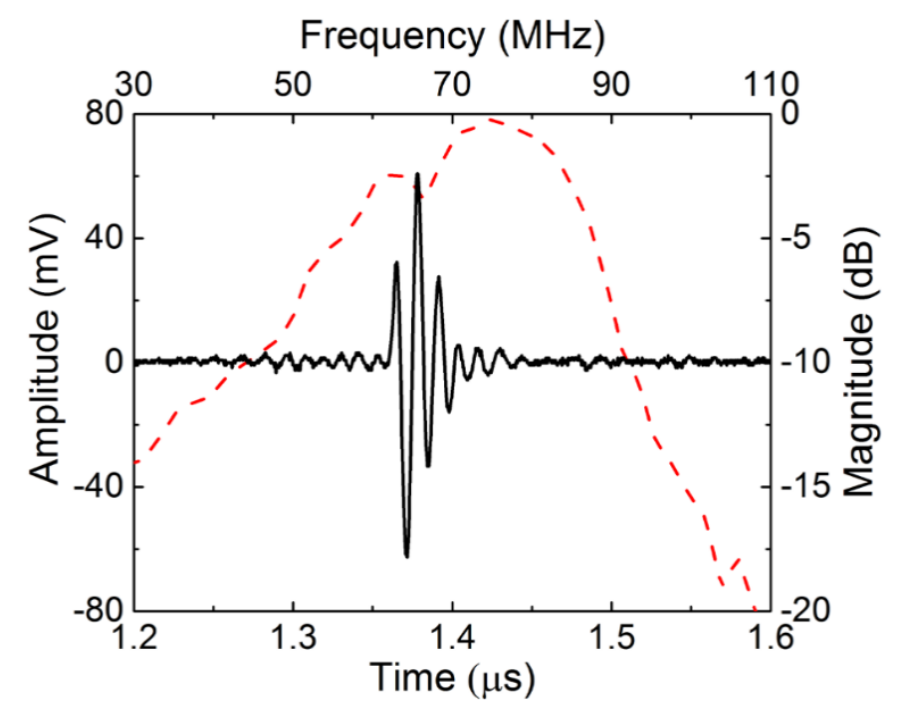

Figure 5. Time-domain pulse/echo response and normalized frequency spectrum of Co-doped $\mathrm{Na}_{0.5} \mathrm{Bi}_{4.5} \mathrm{Ti}_{4} \mathrm{O}_{15}$ (NBT-Co) transducers.

The lateral beam profile of the transducer was evaluated by scanning a wire phantom made of $10 \mu \mathrm{m}$ diameter tungsten wire. The pulse intensity integral (PII) was calculated from the wire target. As shown in Figure 6, a beam width equal to $29.8 \mu \mathrm{m}$ was obtained by the NBT-Co needle transducer in detecting a spatial point target at full width at half maximum (FWHM, $-6 \mathrm{~dB}$ ). In addition, the axial resolution was calculated from the FWHM of the pulse length of the echo to be $20.8 \mu \mathrm{m}$.
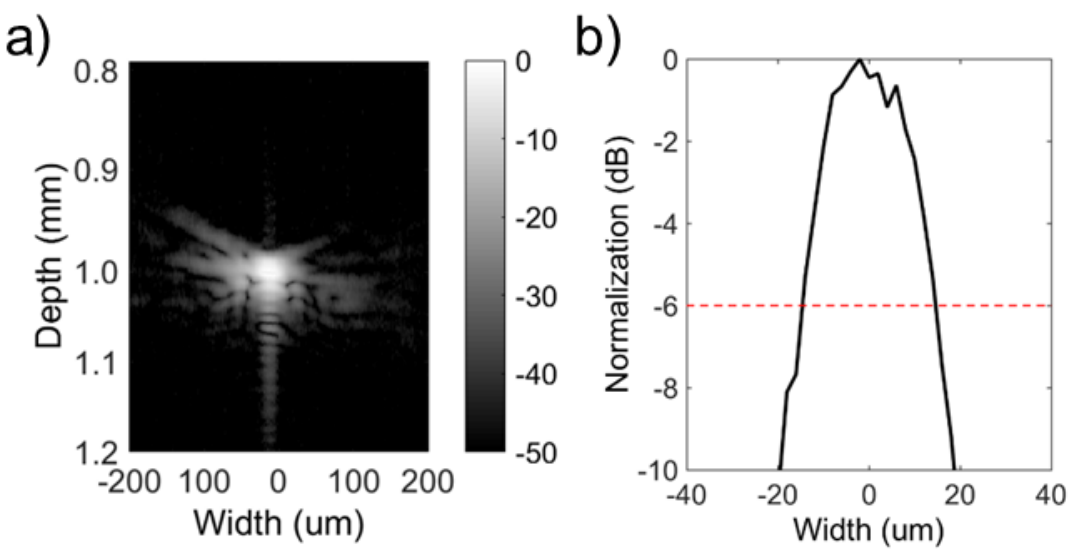

Figure 6. (a) Image of $10 \mu \mathrm{m}$ tungsten wire target; (b) Lateral beam profile of the Co-doped $\mathrm{Na}_{0.5} \mathrm{Bi}_{4.5} \mathrm{Ti}_{4} \mathrm{O}_{15}$ (NBT-Co) transducers.

\section{Conclusions}

Lead-free NBT-Co ceramics were fabricated and investigated systematically. Based on the prepared NBT-Co ceramics, a high frequency and small $f$-number transducer was designed and fabricated. The fabricated transducer has center frequency of $70.4 \mathrm{MHz},-6 \mathrm{~dB}$ bandwidth of $52.7 \%$, and $f$-number close to 1 . Axial resolution of $20.8 \mu \mathrm{m}$ was calculated from the FWHM of the pulse length of the echo, and lateral resolution of $29.8 \mu \mathrm{m}$ was achieved using tungsten wire imaging. These results illustrate that lead-free NBT-Co ceramics have great potential for high frequency ultrasonic applications. 
Author Contributions: C.F., T.Z., C.M.W. and Q.Z. conceived and designed the experiments; D.W., Y.Q. and P.L. performed the experiments; C.F., T.Z and J.C. analyzed the data; D.L., Y.Y. and C.L.W. contributed reagents/materials/analysis tools; C.F. and T.Z. wrote the paper. All authors reviewed the manuscript.

Acknowledgments: Financial support from the National Natural Science Foundations of China (11604251, 11174230), the National Key Project of Intergovernmental Cooperation in International Scientific and Technological Innovation (2016YFE0107900), the Natural Science Foundations of Shannxi Province (2017JQ1006), and Xidian University (XJS16034, XJS17026, JBG161101, JBX171106) , the Fundamental Research Funds of Shandong University (2016JC036, 2017JC032), and a foundation under the Grant No. 2015JMRH0103 are greatly appreciated.

Conflicts of Interest: The authors declare no conflicts of interest.

\section{References}

1. Pavlin, C.J.; Harasiewicz, K.; Sherar, M.D.; Foster, F.S. Clinical use of ultrasound biomicroscopy. Ophthalmology 1991, 98, 287-295. [CrossRef]

2. Foster, F.S.; Lockwood, G.R.; Ryan, L.K.; Harasiewicz, K.A.; Berube, L.; Rauth, A.M. Principles and applications of ultrasound backscatter microscopy. IEEE Trans. Ultrason. Ferroelectr. Freq. Control 1993, 40, 608-617. [CrossRef] [PubMed]

3. Khairy, H.A.; Atta, H.R.; Green, F.D.; Van der Hoek, J.; Azuara-Blanco, A. Ultrasound biomicroscopy in deep sclerectomy. Eye 2005, 19, 555. [CrossRef] [PubMed]

4. Fei, C.L.; Chiu, C.T.; Chen, X.Y.; Chen, Z.Y.; Ma, J.G.; Zhu, B.P.; Shung, K.K. and Zhou, Q.F. Ultrahigh frequency $(100-300 \mathrm{MHz})$ ultrasonic transducers for optical resolution medical imagining. Sci. Rep. 2016, 6, 20360. [CrossRef] [PubMed]

5. Zhu, B.; Fei, C.; Wang, C.; Zhu, Y.; Yang, X.; Zheng, H.; Zhou, Q.; Shung, K.K. Self-Focused AlScN Film Ultrasound Transducer for Individual Cell Manipulation. ACS Sens. 2017, 2, 172-177. [CrossRef] [PubMed]

6. Fei, C.; Hsu, H.S.; Vafanejad, A.; Li, Y.; Lin, P.; Li, D.; Yang, Y.; Kim, E.; Shung, K.K.; Zhou, Q. Ultrahigh frequency $\mathrm{ZnO}$ silicon lens ultrasonic transducer for cell-size microparticle manipulation. J. Alloys Compd. 2017, 729, 556-562. [CrossRef]

7. Zhou, Q.F.; Lau, S.; Wu, D.W.; Shung, K.K. Piezoelectric films for high frequency ultrasonic transducers in biomedical applications. Prog. Mat.Sci. 2011, 56, 139-174. [CrossRef] [PubMed]

8. Zhu, F.; Qiu, J.; Ji, H.; Zhu, K.; Wen, K. Comparative investigations on dielectric, piezoelectric properties and humidity resistance of PZT-SKN and PZT-SNN ceramics. J. Mater. Sci. Mater. Electron. 2015, 26, 2897-2904. [CrossRef]

9. Zhou, Q.; Lam, K.H.; Zheng, H.; Qiu, W.; Shung, K.K. Piezoelectric single crystal ultrasonic transducers for biomedical applications. Prog. Mater. Sci. 2014, 66, 87-111. [CrossRef] [PubMed]

10. Saito, Y.; Takao, H.; Tani, T.; Nonoyama, T.; Takatori, K.; Homma, T.; Nagaya, T.; Nakamura, M. Lead-free piezoceramics. Nature 2004, 432, 84. [CrossRef] [PubMed]

11. Ringgaard, E.; Wurlitzer, T. Lead-free piezoceramics based on alkali niobates. J. Eur. Ceram. Soc. 2005, 25, 2701-2706. [CrossRef]

12. Maeder, M.D.; Damjanovic, D.; Setter, N. Lead free piezoelectric materials. J. Electroceram. 2004, 13, 385-392. [CrossRef]

13. Gao, D.; Kwok, K.W.; Lin, D. Microstructure, piezoelectric and ferroelectric properties of Mn-added $\mathrm{Na}_{0.5} \mathrm{Bi}_{4.5} \mathrm{Ti}_{4} \mathrm{O}_{15}$ ceramics. Curr. Appl. Phys. 2011, 11, S124-S127. [CrossRef]

14. Peng, Z.; Chen, Q.; Wu, J.; Liu, D.; Xiao, D.; Zhu, J. Dielectric properties and impedance analysis in Aurivillius-type $\left(\mathrm{Na}_{0.25} \mathrm{~K}_{0.25} \mathrm{Bi}_{0.5}\right) 1-\mathrm{x}(\mathrm{LiCe}) \mathrm{x} / 2$ [] x/2Bi $\mathrm{Ti}_{4} \mathrm{O}_{15}$ ceramics. J. Alloys Compd. 2012, 541, 310-316.

15. Zhao, T.L.; Guo, Z.L.; Wang, C.M. The Effects of Na/K Ratio on the Electrical Properties of Sodium-Potassium Bismuth Titanate $\mathrm{Na}_{0.5} \mathrm{Bi}_{4.5} \mathrm{Ti}_{4} \mathrm{O}_{15}-\mathrm{K}_{0.5} \mathrm{Bi}_{4.5} \mathrm{Ti}_{4} \mathrm{O}_{15}$. J. Am. Ceram. Soc. 2012, 95, 1062-1067. [CrossRef]

16. Zhao, L.; Xu, J.X.; Yin, N.; Wang, H.C.; Zhang, C.J.; Wang, J.F. Microstructure, dielectric, and piezoelectric properties of Ce-modified $\mathrm{Na}_{0.5} \mathrm{Bi}_{4.5} \mathrm{Ti}_{4} \mathrm{O}_{15}$ high temperature piezoceramics. Phys. Status Solidi (RRL)-Rapid Res. Lett. 2008, 2, 111-113. [CrossRef]

17. Wang, C.M.; Wang, J.F.; Zhang, S.; Shrout, T.R. Electromechanical properties of a-site (LiCe)-modified sodium bismuth titanate $\left(\mathrm{Na}_{0.5} \mathrm{Bi}_{4.5} \mathrm{Ti}_{4} \mathrm{O}_{15}\right)$ piezoelectric ceramics at elevated temperature. J. Appl. Phys. 2009, 105, 094110. [CrossRef] 
18. Chen, H.; Shen, B.; Xu, J.; Zhai, J. Textured $\mathrm{Ca}_{0.85}(\mathrm{Li}, \mathrm{Ce})_{0.15} \mathrm{Bi}_{4} \mathrm{Ti}_{4} \mathrm{O}_{15}$ ceramics for high temperature piezoelectric applications. Mater. Res. Bull. 2012, 47, 2530-2534. [CrossRef]

19. IEEE Standard on Piezoelectricity (ANSI/IEEE Standard No. 176, 1987).

(C) 2018 by the authors. Licensee MDPI, Basel, Switzerland. This article is an open access article distributed under the terms and conditions of the Creative Commons Attribution (CC BY) license (http://creativecommons.org/licenses/by/4.0/). 